was associated with higher serum concentrations of IL-17A ( $p=0.01$ ), irrespective of the presence of HLA-B27, CRP and IL-6 (both $p<0.05)$ but not TNFa $(p=0.2)$. Conclusions: In a cross-sectional study, the presence of IgA Abs against CD74 was associated with serum levels of pro-inflammatory biomarkers such as CRP (and IL-6) and IL-17 but not TNFa irrespective of HLA-B27 status. Longitudinal prospective studies are needed to show that the measurement of IgA anti-CD74 Abs and/or serum cytokines can help to guide treatment decisions.

Acknowledgements: We thank Novartis Pharma AG for the support of our study.

Disclosure of Interest: X. Baraliakos: None declared, K. Kniesch: None declared, N. Baerlecken: None declared, J. Braun: None declared, T. Witte Grant/ research support from: Novartis

DOI: 10.1136/annrheumdis-2018-eular.5570

\section{AB0897 THE RELATIONSHIP BETWEEN DISEASE-SPECIFIC INDICES AND BALANCE IN PATIENTS WITH ANKYLOSING SPONDYLITIS}

Y. Acar ${ }^{1}$, N. İlçin ${ }^{1}$, B. Gürpınar ${ }^{1}$, G. Can ${ }^{2}$, F. Önen ${ }^{2} .{ }^{1}$ Physical Theraphy and Rehabilitation; ${ }^{2}$ Rheumatology, Dokuz Eylül University, izmir, Turkey

Background: Axial and periferal joint stifness, impaired joint mobility and postural deformities may affect balance in AS. However factors affecting balance in AS patients are still unclear. There is limited literature investigating balance-related factors in patients with AS and the results are contradictory.

Objectives: The aim of the study was to investigate relationship between disease-specific indices and balance in patients with AS.

Methods: 72 patients(46 male, 26 female) with AS were included in the study. The demographic and anthropometric features(age, weight, height, body mass Index(BMI)) of patients were recorded. Disease-specific indices used in the study were Bath Ankylosing Spondylitis Disease Activity Index (BASDAI), Bath Ankylosing Spondylitis Functional Index (BASFI) and Bath Ankylosing Spondylitis Mobility Index (BASMI). BASDAI for disease activity, BASFI for functional capacity, BASMI for spinal mobility were used. Static and dynamic balance was evaluated with Biodex Balance System SD. Limits of stability and bilateral stance (stable and unstable platform), single leg stance (stable platform) postural stability test results were recorded. Overall stability $(\mathrm{OA})$ indices were used. A high score in the OA index indicates poor balance. Spearman correlation test used for statistical analysing. Correlation analyses were performed between BASDAI, BASFI, BASMI scores and Biodex test results

Results: The mean age of patients was $39,95 \pm 8,84$ years and mean BMI was $26,55 \pm 3,82 \mathrm{~kg} / \mathrm{m}^{2}$. BASDAI, BASFI and BASMI scores of patients are shown in table 1.

Abstract AB0897 - Table 1. BASDAI, BASMI and BASFI scores

\begin{tabular}{lc}
\hline & $\begin{array}{c}\text { AS patients }(\mathrm{n}=72) \\
\text { Median }(\text { IQR 25- } \\
\end{array}$ \\
\hline BASDAI & $75)$ \\
BASFI & $2,10(1,02-3,78)$ \\
BASMI & $1,10(0,30-2,74)$ \\
\hline
\end{tabular}

Only positive weak correlation was found between BASFI score and right leg stance overall postural stability index $(r=0,25, p=0,034)$. No other correlation was detected between BASDAI, BASFI, BASMI scores and Biodex balance test results.

Conclusions: The results of our study indicated that there is no relationship between BASDAI, BASFI, BASMI scores and balance except BASFI score and right leg stance postural stability. Our results contradict some previous studies while supporting some studies. This may be due to in our study BASDAI, BASFI and BASMI scores are lower than previous studies or the usage of different methods from previous studies for evaluating balance and postural stability in AS. Further studies are required to establish the actual status of relationship between balance and clinic measurements in AS patients.

\section{REFERENCE:}

[1] Pompeu, J.E., Static and dynamic balance in subjects with ankylosing spondylitis: literature review. Revista brasileira de reumatologia, 2012. 52 (3): p. 413-416.

Disclosure of Interest: None declared DOI: 10.1136/annrheumdis-2018-eular.5126

\section{AB0898 \\ COURSE OF ANKYLOSING SPONDYLITIS IN PREGNANCY}

Z. Gandaloeva, O. Kritchevskaya, T. Dubinina, S. Erdes. Laboratory of spondyloarthritis, V. A. Nasonova Research Institute of Rheumatology, Moscow, Russian Federation

Objectives: To study the effect of pregnancy on ankylosing spondylitis (AS) course.

Methods: 86 AS patients having pregnancy in the course of the disease were included into questionnaire survey. Patients' mean age was 34 [30:37] years mean disease duration was 120 [72:180] month. The questionnaire items were designed to elucidate modifications in AS course during the last pregnancy with live birth outcome. The study is based on patient's self-reported health (SRH) status (improvement, worsening, no change).

Results: All responders reported delivery of full-term babies at mean 39 weeks [38:40] of gestation, vaginal delivery was documented by $46(53,5 \%)$ responders, Caesarean section - by 40 (46,5\%). AS worsening or improvement during all three trimesters is shown in the table 1.

Abstract AB0898 - Table 1

\begin{tabular}{lcc}
\hline Trimester & Improvement $\mathrm{n}=42 /$ & Worsening $\mathrm{n}=58$ / \\
& $48,8 \%$ & $67,4 \%$ \\
\hline I & $30 / 34,8 \%$ & $15 / 17,4 \%$ \\
II & $21 / 24,4 \%$ & $26 / 30,2 \%$ \\
III & $18 / 20,9 \%$ & $36 / 41,8 \%$ \\
\hline
\end{tabular}

Comparison of improvement rates in I and III trimesters, $\mathrm{p}=0,05$

Worsening of underlying disease (as compared to the condition 3 months prior to pregnancy) during whole pregnancy was reported by $3(3,5 \%)$ women, absence of noticeable changes was reported by $13(15,1 \%)$ patients, and AS improvement - by $9(10,4 \%)$ participants.

$61(71 \%)$ of responders reported fluctuating AS activity during pregnancy. AS worsening was associated with exacerbation of back pain in $44(51 \%)$, emergence and/or recurrence of arthritis - in $15(17,4 \%)$, or uveitis - in $9(10,4 \%)$, and other symptoms - in $11(12,8 \%)$ patients.

Conclusions: Therefore, the majority of participants reported the diverse fluctuations in AS course during pregnancy, although $50 \%$ of responders reported the improvement in the course of the disease at least during one trimester (more often in the first). Nevertheless, almost $70 \%$ of responders reported AS worsening with exacerbations rates increasing in parallel with increasing gestation age. $50 \%$ of participants noticed worsening back pain, although special attention should be given to correct evaluation of AS activity in these patients keeping in mind the increased physiological load on the backbone during the second half of pregnancy.

Disclosure of Interest: None declared

DOI: 10.1136/annrheumdis-2018-eular.1968

\section{AB0899 ANKYLOSING SPONDYLITIS AND PREGNANCY: DATA FROM THE QUESTIONNAIRE SURVEY-BASED PILOT STUDY}

Z. Gandaloeva, O. Kritchevskaya, T. Dubinina, N. Kosheleva, S. Erdes. laboratory of spondyloarthritis, V. A. Nasonova Research Institute of Rheumatology, Moscow, Russia., Moscow, Russian Federation

Objectives: To study parity and pregnancy outcomes, as well as causes for not getting pregnant in women with ankylosing spondylitis (AS).

Methods: 326 AS female patients were covered by questionnaire survey during the period from November 2016 until October 2017. Mean age of the participants was 32 [28:36] years, mean AS duration - 102 [48:168] months. The questionnaire items covered such issues as prior pregnancies, maternal and neonatal outcomes and potential reasons for not getting pregnant.

Results: 194 (59\%) (mean age $34,1 \pm 5,4$ y) females out of 326 surveyed had from 1 to 8 pregnancies, totally 396 . Pregnancy outcomes are presented in the table 1 . 
Abstract AB0899 - Table 1

\begin{tabular}{|c|c|c|c|}
\hline \multirow[b]{2}{*}{ before AS onset $n=185$} & \multicolumn{2}{|c|}{ Number of pregnancies $(n=396)$} & \multirow[t]{2}{*}{$p$} \\
\hline & $\begin{array}{c}\text { after AS onset } \\
\mathrm{n}=211\end{array}$ & & \\
\hline Childbirth: $n / \%$ & $100 / 54 \%$ & $143 / 67,8 \%$ & 0004 \\
\hline -vaginal delivery $n$ & $\begin{array}{l}76 \text { ( } 76 \% \text { of } \\
\text { deliveries) }\end{array}$ & $\begin{array}{c}78 \text { ( } 54,5 \% \text { of } \\
\text { deliveries) }\end{array}$ & 0,0005 \\
\hline - Caesarean section $n$ & $\begin{array}{l}24 \text { (24\% of } \\
\text { deliveries) }\end{array}$ & $\begin{array}{c}65 \text { ( } 45,5 \% \text { of } \\
\text { deliveries) }\end{array}$ & 0,0008 \\
\hline Woman's choice abortion & $61 / 33 \%$ & $30 / 14,2 \%$ & 0,0000 \\
\hline Unfavourable maternal outcome * & $24 / 13 \%$ & $38 / 18 \%$ & 0,17 \\
\hline Neonate's birth weight $[M e \pm I Q R](\mathrm{g})$ & $3240[3050: 3600]$ & $3.260[2950: 3600]$ & 0,3 \\
\hline $\begin{array}{l}\text { Neonate's birth length }[M e \pm I Q R] \\
(\mathrm{cm})\end{array}$ & $52[51: 53]$ & $51[50: 52]$ & 0,02 \\
\hline $\begin{array}{l}\text { Apgar score at } 1 \text { min after birth }[\mathrm{Me} \\
\pm I Q R]\end{array}$ & $8[7: 8]$ & $8[7: 8]$ & 0,8 \\
\hline
\end{tabular}

* - non-developing pregnancies, spontaneous abortions, medical abortions and preterm births.

There were no pregnancies in 132 (41\%) surveyed females (mean age 29,1 $\pm 5,4 \mathrm{y})$.

Reasons and causes for not getting pregnant in 132 AS females:

- $48 \%$ cases - social, household/domestic and familial, including spouses' unwillingness to have children;

- 44\% - presence of AS (fear of teratogenic effect of pharmacotherapeutic agents

$-18 \%$, fear of AS inheriting by the baby $-3 \%$, physician's forewarnings $-8 \%$, a combination of abovementioned causes $-15 \%$ );

$-8 \%$ - infertility.

Conclusions: Therefore, data from questionnaire survey of females with AS demonstrates that presence of AS does not increase the incidence of unfavourable maternal outcomes of pregnancies, or negatively affects anthropometric parameters of neonates. Of notice is the fact, that women's choice abortions become more rare after AS diagnosis is established. The rate of Caesarean sections is higher in AS patients. Fear of potentially harmful effects of the disease and it's therapy on the fetus and the baby underlies $30 \%$ of all not getting pregnant cases among AS female patients of child-bearing age.

Disclosure of Interest: None declared

DOI: 10.1136/annrheumdis-2018-eular.1967

\section{Psoriatic arthritis}

\section{AB0900 DESCRIPTIVE STUDY OF PSORIATIC ARTHRITIS IN A HISTORICAL COHORT OF 383 PATIENTS AT A UNIVERSITY HOSPITAL}

A. Prior Español ${ }^{1}$, L. Mateo ${ }^{1}$, M. Mihaylov ${ }^{1}$, J. Roca ${ }^{2}$, Y. García Mira ${ }^{1}$, J. Camins ${ }^{1}$,

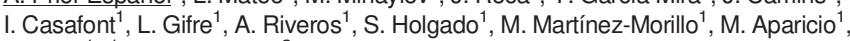
A. Olivé ${ }^{1}{ }^{1}$ Rheumatology; ${ }^{2}$ Epidemiology, Hospital Germans Trias i Pujol, Badalona, Spain

Background: There are few recent large cohort epidemiological studies that analyse the clinical profile of patients with psoriatic arthritis $(\mathrm{PsA})$ who require biological treatment, as well as pharmacological survival and reasons for the suspension of these treatments.

Abstract AB0900 - Table 1

\begin{tabular}{lccc}
\hline $\mathrm{N}$ & 383 & \multicolumn{2}{c}{ Basal radiological involvement } \\
\hline Age at PsA (years), mean (SD) & $45.9(14.5)$ & Erosive arthritis (\%) & 33.1 \\
\hline Male sex, $\mathrm{n}(\%)$ & $203(53)$ & Mutilating arthritis (\%) & 1.9 \\
History of psoriasis (\%) & 84.8 & Sacroilitis (\%) & 21.2 \\
Nail involvement (\%) & 46.3 & Syndesmophytes (\%) & 5 \\
Dactylitis (\%) & 32.9 & Immunity & \\
Enthesitis (\%) & 36.9 & RF positive (\%) & 6.3 \\
DAS-28 (ESR), mean (SD) & $3.5(1.46)$ & ANA positive (\%) & 14.5 \\
CRP mg/L, mean (SD) & $8.11(15.9)$ & HLA B27 positive (\%) & 14.1 \\
ESR mm/h, mean (SD) & $20.3(19.2)$ & Treatment & \\
Comorbidities & & NSAID (\%) & 96.7 \\
Dyslipidemia (\%) & 34.2 & csDMARDs (\%) & 84.8 \\
AH (\%) & 20.9 & bDMARDs (\%) & 32.3 \\
Obesity (\%) & 28.2 & &
\end{tabular}

CRP: C-reactive protein; ESR: erythrocyte sedimentation rate; $\mathrm{AH}$ : arterial hypertension; RF rheumatoid factor; ANA: anti-nucleotide antibodies; NSAID: non- steroidal anti-inflammatory drugs; csDMARDs: conventional synthetic diseasemodifying antirheumatic drugs; bDMARDs: biological disease-modifying antirheumatic drugs.

Objectives: To describe the clinical, demographic, epidemiological and radiographic characteristics of patients with PsA in our centre, as well as pharmacological survival and reasons for the suspension of different biological treatments.

Methods: Retrospective analysis of patients with PsA treated between 1985 and 2015 at a University Hospital with a referral area of 850000 inhabitants. Demographic, clinical, laboratory and imaging data, as well as patients' clinical and medical treatment records.

Results: The main characteristics of the cohort are summarised in table 1:

Approximately one third of patients with PsA (32.3\%) required treatment with a biological drug during the course of their disease. The most frequently prescribed first-line drugs (89.5\%) were tumour necrosis factor- $\alpha$ inhibitors (TNFi).

During the course of their disease, 27 (21.9\%) patients who started biological treatment received a biological drug other than TNFi. Of the 124 patients who started treatment with a biological DMARD, more than half $(65,52.8 \%)$ required a change to a second drug, and of these, $27(41.5 \%)$ changed to a third, with up to 7 different biological drugs required in one case. The mean survival time for the first bDMARD was $42.8 \pm 42.3$ months, with secondary failure the most frequent cause of treatment change $(37.8 \%)$, followed by adverse effects $(27.1 \%)$ and primary failure (18.9\%). The adverse effects registered were: $20 \%$ infections, $20 \%$ appearance of neoplasms, $5 \%$ allergic reactions and $55 \%$ other causes.

Conclusions: PsA presents a similar distribution by sex and is usually diagnosed at around the age of 50 , having been preceded by cutaneous involvement. PsA is an entity of considerable severity and up to a third of patients will require biological treatments during its evolution. More than half of them will receive a second biological treatment. The retention rate of each drug varies but tends to decrease with each drug change.

Disclosure of Interest: None declared

DOI: 10.1136/annrheumdis-2018-eular.4393

\section{AB0901 VASPIN AND LIPOCALIN2 LEVELS IN PSORIATIC ARTHRITIS}

S. Colak ${ }^{1}$, A. Omma ${ }^{1}$, S. Can Sandikci², C. Yucel ${ }^{3}$, T. Turhan ${ }^{3} .{ }^{1}$ Rheumatology, Ankara Numune Training and Research Hospital; ${ }^{2}$ Rheumatology, Dıskapı Yıldırım Beyazıt Training and Research Hospital; ${ }^{3}$ Biochemistry, Ankara Numune Training and Research Hospital, Ankara, Turkey

Background: Psoriathic athritis (PsA) is a type of spondiloarthropaties which is affiliated with psoriasis. Metabolic syndrome, diabetes mellitus and cardiovascular diseases are comorbid conditions associated with psoriatic arthritis. Adipokines are suggested to be playing proinflammatory or antiinflammatory roles in the proceeding of inflammatory situations.

Objectives: The aim of this study is to investigate the recently interested adipokines vaspin and lipocalin2 levels and their association with disease activity of patients diagnosed with psoriatic arthritis.

Methods: The study was conducted between October 2017 and January 2018 at the Rheumatology Clinic of Ankara Numune Training and Research Hospital, Turkey. The vaspin and lipocalin2 levels of 50 PsA patients, diagnosed according to the Classification Criteria for Psoriatic Arthrtis (CASPAR), and 36 age-and sexmatched healthy subjects were analysed in current study. The disease activity was assessed by using Psoriasis Area Severity Index, Bath Ankylosing Spondylitis Functional Index, Bath Ankylosing Spondylitis Disease Activity Index and Dis ease Activity Index for Psoriatic Arthritis. Indexes were applied to the patients in order to evaluate the disease activity.

Results: No significant difference was found between groups with respect to age, sex and body mass index. There was significant difference between vaspin $(p=0.001)$ and lipocalin2 $(p=0.014)$ levels among the PsA patients and contro groups. There was no significant difference between the groups in terms of disease activity $(p>0.05)$.

Abstract AB0901 - Table 1. The clinical and laboratory parameters in two groups.

\begin{tabular}{lccc}
\hline & PsA patients $(n=50)$ & Healthy subjects $(n=36)$ & P value \\
\cline { 2 - 3 } & Mean $( \pm$ SD $)$ & Mean $( \pm$ SD $)$ & \\
\hline Males/Females & $15 / 35$ & $11 / 25$ & 0956 \\
Age (years) & $44.58(13.88)$ & $43.08(11.03)$ & 0,57 \\
Vaspin $(\mathrm{ng} / \mathrm{L})$ & $391.63(436.4)$ & $176.67(122.75)$ & 0.001 \\
Lipocalin2 $(\mathrm{ng} / \mathrm{L})$ & $5.2(2.67)$ & $1.94(2.09)$ & 0.014 \\
\hline
\end{tabular}

PsA: Psoriatic Arthritis, SD:Standard deviation

Conclusions: The results of this study points out the possible role of vaspin and lipocalin2 in PsA. In our knowledge, this is the first study comparing the vaspin and lipocalin2 levels of patients with PsA to healthy subjects and these findings 